\title{
A narrativa foto(etno)gráfica como discurso: um relato da agricultura familiar da Ilha dos Marinheiros sob uma perspectiva estrutural
}

Jandré Corrêa Batista ${ }^{1}$

Resumo: O presente trabalho trata da importância do uso da fotografia em trabalhos etnográficos, enaltecendo a proposta de Achutti $(1997 ; 2004)$ no que se refere ao uso da fotografia como instrumento narrativo, a partir de um estudo concreto: a producação agrícola da Ilha dos Marinheiros (município de Rio Grande, Rio Grande do Sul, Brasil). Nos moldes de Bateson e Mead (1942), apresentar-se-á uma narrativa estrutural (SAMAIN, 2004) sobre as particularidades sociais que norteiam o processo produtivo naquela localidade.

Palavras-chave: antropologia visual, etnografia, fotografia.

Abstract: This paper argues about the importance of using photography in the ethnographic perspective, endorsing the thoughts of Achutti $(1997,2004)$ about the uses of photography as a fundamental narrative instrument. We focus in the the agricultural production of Ilha dos Marinheiros (city of Rio Grande, Rio Grande do Sul, Brazil). Based on Bateson and Mead (1942), we will present a structural narrative (SAMAIN, 2004) about the social peculiarities that guide the production process in that locality.

Keywords: visual antropology, ethnography, photography. 
Parte-se para a realização deste trabalho de uma perspectiva cultural das ciências da comunicação, baseada na natural relação dialógica entre comunicação e antropologia (WINKIN, 1998), especificamente quanto à dimensão visual do fazer etnográfico. De acordo com Samain (1998), "pensar antropologicamente a comunicação humana significa (...) investigar etnograficamente os comportamentos, as situações, os objetos que, numa comunidade dada, são percebidos como valores comunicativos". Nesse sentido, opta-se por um olhar cultural sobre a comunicação: não como um processo individual, teleférico, mas como a prática de uma "leitura comunicacional do mundo social" (SAMAIN, 1998, p. 10). Neste caso, a partir da utilização do visual - a narrativa fotográfica - como representação da alteridade.

Como leitura comunicacional, utilizou-se na presente pesquisa o suporte fotográfico em uma perspectiva antropológica como forma narrativa: a fotoetnografia². Como delimitação do mundo social para a constituição de um objeto de estudo, abordou-se os aspectos referentes à agricultura familiar na Ilha dos Marinheiros (município de Rio Grande, Rio Grande do Sul, Brasil). A opção por essa localidade se deu em decorrência de suas características culturalmente peculiares, especialmente no que tange ao processo de produção agrícola.

Conforme consta em Achutti (1997; 2004), a fotografia é um ato permanente de fragmentação de elementos de uma determinada realidade em um plano. Segundo o autor, essa característica aliada ao olhar etnográfico é capaz de conduzir ao desenvolvimento de uma forma narrativa mais aprofundada, não se restringindo apenas ao texto na construção de sentidos e à fotografia como ferramenta de pesquisa de campo, mas também à imagem como discurso. Sendo possível, na construção de uma narrativa visual, ter-se maior eficácia na difusão dos resultados obtidos.

Partindo desse pressuposto, apresenta-se o registro fotográfico na Ilha dos Marinheiros, especificamente sobre a produção de hortifrutigranjeiros - de 
forma a englobar todos os estágios da produção: desde o preparo da terra, o cultivo, a irrigação, a colheita, a organização do trabalho, o transporte, até o momento da comercialização da produção. Conforme definição de Samain (2005), apresentar-se-á a construção de uma narrativa estrutural (nos moldes de BATESON \& MEAD, 1962) registrada naquela localidade insular.

\section{Por uma outra forma de contar}

A arte de descrever o homem em suas relações sociais, abstraindo-se o conceito $^{3}$ imoral de "etnografia" do século XIX, iniciou-se com Bronislaw Malinowski na segunda década do século XX. Suas principais contribuições, o que constitui uma revolução ao que até então se entendia por etnografia, remetiam ao entendimento da vida do outro na tentativa, por meio muitas vezes de uma observação participante, de compreender o mundo a partir do ponto de vista daquele que se intenta estudar. A partir de Malinowski, o procedimento etnográfico passou então a ser entendido como um "estar junto" à cultura do pesquisado. Essa absorção à cultura local reverenciada e inaugurada por Malinowski é claramente observada em "Argonautas do Pacífico Ocidental"4.

Malinowski, reverenciado como o pai da antropologia, utilizava em seu trabalho de campo não só a descrição textual, o que se tornou clássico em antropologia, mas também, apesar de suas limitações ${ }^{5}$ e aversão ao uso, a fotografia. Embora a relação desse autor com a fotografia não seja íntima, conforme consta em Samain (1995), em "Argonautas do Pacífico Ocidental" (Malinowski, 1976) um conjunto considerável de pranchas fotográficas foi utilizado em transposição à barreira da mera ilustração e em recorrência à imagem como fragmentação da realidade.

Percebe-se, portanto, no nascimento da antropologia, apesar da aversão ao uso da imagem - resistência reproduzida consideravelmente até hoje em trabalhos etnográficos -, o caráter fundamental da fotografia em representar 
a sociedade do outro em substituição a narrativas textuais prolixas que jamais superariam o potencial descritivo da imagem (ACHUTTI, 2004).

Winkin (1998), a partir do modelo orquestral de comunicação, propõe uma metodologia específica para a "saída de campo". A proposta consiste na escolha de um lugar público em que se possa observar a comunicação em ação, não necessariamente participante, a fim de constatar a ocorrência de padrões de comportamento. O registro dessa constatação deverá ser traduzido exclusivamente ${ }^{6}$ para diários escritos, os quais funcionarão como um elemento de catarse ao observador. Esse procedimento etnográfico, segundo o próprio autor, é um trabalho que exige "que se saiba retraduzir para um público terceiro (...) e portanto que se saiba escrever" (WINKIN, 1998, p. 132).

Embora Winkin (1998) proponha uma visão ampliada e ao mesmo tempo inerente aos estudos em comunicação em sua articulação com a Antropologia, não há também uma visão redimensionada com relação ao fazer etnográfico. A proposta metodológica desse autor insere no campo dos estudos em comunicação a concepção do clássico texto etnográfico como único elemento capaz de fazer a mediação de uma cultura a outra. O que se propõe elucidar, portanto, é uma nova forma do "saber escrever" referido por Winkin (1998, p. 132); o "saber escrever" com a luz: a utilização de narrativas fotográficas em uma perspectiva discursiva.

O que confere uma tal supremacia ao texto e à palavra são, evidentemente, as práticas acadêmicas de sempre cuja pertinência científica jamais é posta em questão, mas também a falta de domínio de outras técnicas. Nesse caso, não se trata de buscar uma alternativa ao texto escrito, nem de provocar um "duelo" entre texto e imagem, mas de salientar o fato de que, mesmo que o texto seja fundamental, sua associação a outras formas de linguagem não pode senão enriquecer os enunciados antropológicos (ACHUTTI, 2004, p. 94).

Embora não caracterize a utilização da imagem em uma perspectiva discursiva (não ultrapassando a utilização da fotografia 
como ferramenta de pesquisa/coleta de dados), torna-se fundamental para esse entendimento a contribuição de Collier Jr. (1973) em relação à relevância do uso da fotografia em trabalhos antropológicos como elemento possibilitador de uma observação crítica:

\footnotetext{
Indiscutivelmente, a cegueira pessoal que obscurece nossa visão individual está relacionada com o isolamento que é possível em nossa sociedade urbana e mecanicista. Aprendemos a ver apenas o que praticamente precisamos ver. Atravessamos nossos dias com viseiras, observando somente uma fração do que nos rodeia. E quando observamos criticamente, é quase sempre com o auxílio de alguma tecnologia (COLLIER JR., 1973, p. 3).
}

Se formos analisar a fala de Collier Jr. (1973) à luz da contemporaneidade, perceber-se-á a fundamental importância do uso de novos suportes comunicacionais no registro etnográfico. Em uma sociedade dita pós-moderna que contempla o efêmero, a análise antropológica das culturas dependerá essencialmente do visual para se reinventar e assim não esvaecer. Nesse sentido, Achutti (2004), defensor da utilização da fotografia de forma narrativa em antropologia, argumenta que a cultura da imagem (referindo-se à consagração do visual como linguagem cotidiana, a partir das novas percepções sensoriais de tempo e espaço propiciadas pelas novas tecnologias) deve ser entendida também a partir de imagens, e que a antropologia, ciência em constante mutação, teria de estar nesse sentido alinhada às novas dinâmicas sociais das populações. Para esse autor, a conseqüência direta da proposta de incorporação do visual à antropologia consistiria na maior difusão do trabalho etnográfico em função do caráter universal inerente à linguagem fotográfica.

\section{Acerca do método: discussão e procedimentos}

Para a coleta de dados no trabalho de campo, partiu-se da obra de John Collier Jr., Antropologia Visual: a fotografia como método de pesquisa (1973). Esse autor tece importantes orientações de como abordar os atores sociais no 
uso da fotografia em pesquisas etnográficas, principalmente no que se refere à construção de uma interação entre o sujeito fotografado e o operador. Para a construção de narrativas fotográficas, utilizou-se como referencial a obra "The Balinese Character: a photographic analysis" (BATESON \& MEAD, 1942), pioneira no que se refere à construção de trabalhos etnográficos através de um conjunto de fotografias de forma narrativa. Obra icônica de autoria de Gregory Bateson e Margareth Mead, foi o primeiro trabalho, de caráter descritivo ainda sem igual, a explorar o potencial narrativo da fotografia em um trabalho etnográfico e a entender "a fotografia como forma narrativa indispensável" em Antropologia (ACHUTTI, 2004, p. 104).

A retratar o ethos da Ilha de Bali (Indonésia), a obra configura-se em 100 pranchas fotográficas temáticas que descrevem os processos singulares de incorporação social submetidos às crianças daquela comunidade, a fim de serem reconhecidas como membros e legitimadas pela sociedade. Segundo definição de Samain (2004), há basicamente dois modelos de disposição das fotografias em "Balinese Character": o modelo seqüencial e o modelo estrutural. Essas duas concepções de uso da narrativa fotográfica diferem-se no seguinte sentido: enquanto o modelo seqüencial retrata um acontecimento de forma linear, o modelo estrutural liga imagens aparentemente sem uma seqüência lógica a um determinado sentido comum. Canevacci (2001, p. 65-66), a respeito do trabalho de Bateson e Mead, afirma que "é possível sustentar, de fato, que com esse texto ("Balinese Character") firma-se a passagem da antropologia visual, em sentido técnico, à antropologia da comunicação em sentido metodológico".

Apesar de "Balinese Character" datar do final da primeira metade do século passado, a abordagem visual em Antropologia ainda é muito recente. Conforme cita Achutti (2004), há uma canonização do texto etnográfico como linguagem única para retratar a alteridade. Quando utilizadas, as imagens são dispostas de maneira redundante ao texto, assumindo o papel de meras ilustrações. 0 texto, em vez de complementar o que é expresso pela imagem, passa apenas a reiterar de forma redundante a informação já transmitida pela fotografia. 
Um trabalho etnográfico, em oposição, cunhado por esse autor de "Fotoetnografia", configurar-se-ia em uma série de fotografias dispostas de forma narrativa. Achutti (2004) defende que a fotografia enquanto discurso deve ser entendida em sua forma homogênea, e que qualquer outro tipo de linguagem que possa vir a dividir espaço ( $\mathrm{e}$ a isso se incluem as legendas) tenderá a esvaecer o potencial de absorção propiciado pela narrativa.

No entanto, nessa proposta metodológica não é objetivo extinguir o papel do tradicional texto etnográfico. Para Achutti (2004), uma narrativa textual que contextualize o assunto abordado pelas fotografias poderá vir a ser construída, desde que seja constituída isoladamente. Não como instrumento, mas como discurso: a fotografia em decorrência do próprio caráter inerentemente antropológico da imagem. Em detalhamento a esse axioma em relação à fotografia, Samain afirma (1993, p.6, apud ACHUTTI, 2004, p. 83):

\footnotetext{
Não existem fotografias que não sejam portadoras de um conteúdo humano e, conseqüentemente, que não sejam antropológicas à sua maneira. Toda fotografia é um olhar sobre o mundo, levado pela intencionalidade de uma pessoa, que destina sua mensagem visível a um outro olhar, procurando dar significação a este mundo.
}

Nessa proposta, apropriando-nos da obra de Mcluhan (1979), a comunicação visual passa a ser entendida não como uma mera representação da realidade, mas como uma extensão desta. A fotografia enquanto instrumento narrativo constituiria-se assim de uma "extensão" do olhar. "É fato que o homem conhece o mundo agindo sobre ele e para tal ação, ele cria extensões de seus sentidos, aumentando seu conhecimento no tempo e no espaço" (FERREIRA, 2002, p. 8).

\section{O objeto: delimitação, aspectos históricos, sociais e econômicos}

A Ilha dos Marinheiros está localizada na margem oeste da Laguna dos Patos. Situa-se a $32^{\circ} 00^{\prime}$ de latitude sul e $52^{\circ} 6^{\prime}$ de longitude oeste. 
Possui área de $39,28 \mathrm{~km}^{2}$ e contorno de aproximadamente $26 \mathrm{~km}$ de estrada de terra?. Pertence ao $2^{\circ}$ distrito da cidade de Rio Grande (estado do Rio Grande do Sul), distanciando-se do continente 1,5 km por via lacustre e 9 $\mathrm{km}$ por terra. Divide-se basicamente em quatro sub-regiões bem definidas: Bandeirinhas (Oeste), Porto do Rey (Sul), Marambaia (Leste) e Fundos da Ilha (Norte); também em duas localidades intermediárias denominadas pelos próprios habitantes de Coréia (entre Marambaia e Fundos da Ilha) e Fredericks (entre Porto do Rey e Marambaia).

Formada a partir da acumulação de segmentos, a Ilha dos Marinheiros é a maior e mais importante ilha da Laguna dos Patos, tendo sido, inclusive, a área agrícola mais ativa na produção de hortifrutigranjeiros no que se refere ao abastecimento do município de Rio Grande e à exportação (AZEVEDO, 2003).

Uma das maiores peculiaridades da Ilha dos Marinheiros é o valor dado por seus habitantes à tradição. Por três séculos, de geração a geração, dá-se continuidade aos costumes da colonização portuguesa do século XIX (AZEVEDO, 2003), tanto no que tange aos aspectos relacionados à produção familiar de hortifrutigranjeiros, tema desta pesquisa, quanto aos hábitos religiosos de suas gentes. Tendo em vista a continuidade dos valores culturais dos habitantes da Ilha dos Marinheiros, fato explicado em parte pelo isolamento histórico ao continente, parte-se do pressuposto de que para um entendimento satisfatório de nosso objeto de estudo se faz necessário traçar um paralelo com a progressão histórica da Ilha, em face ao inquestionável diálogo entre as relações de produção de hoje com a bagagem cultural de seus praticantes.

A vinda em grande escala de imigrantes europeus para o Brasil foi determinada pelas complexas transformações que ocorreram na Europa na segunda metade do século XIX. Uma dessas transformações, a expansão do liberalismo, provocou a saída dos trabalhadores rurais do continente (CORRÊA, 2005). Esses lavradores, proprietários de pequenos lotes de terra, "sem condições de produzir o sustento da família no espaço agrícola e sem emprego na cidade, foram expulsos da Europa" (ZANOTELLI, 2003, p. 224). 
Outro elemento que colaborou para o êxodo da Europa para a América, sobretudo o dos trabalhadores rurais, foi o acréscimo dos impostos sobre os produtos agrícolas. Essa situação provocou a miséria da população rural. Dessa forma, por questão de sobrevivência, os agricultores almejavam migrar para um local onde pudessem retomar a sua produção de forma digna (CORRÊA, 2005). Uma das alternativas era a imigração ao Brasil. Em plena crise agrária européia, o governo brasileiro incentivava fortemente a imigração, anunciando a abundância de terras agricultáveis. Essa realidade pôde ser observada pelo fluxo migratório ocorrido na Ilha dos Marinheiros a partir da segunda metade do século XIX, período que ficou conhecido "como o maior movimento migratório internacional da história dos povos" (BRITTO, 1995, p. 55). Tais condições, na realidade migratória da Ilha dos Marinheiros, são apontadas por Azevedo (2003, p. 43):

\footnotetext{
Cada vez mais foram chegando portugueses, vindos do norte de Portugal, donos de muita força de vontade e espírito aventureiro Lançam-se ao mar para desbravar estas terras, engrossando cada vez mais a população da Ilha, que atingiu 9800 habitantes, segundo os mais antigos (...).
}

A escolha pela ocupação da Ilha dos Marinheiros se deu principalmente pela então recente inserção da viticultura na região e pelas condições ambientais favoráveis à produção agrícola. Desce cedo, através de esforços governamentais a Ilha já tinha as suas terras transformadas pela agricultura. Historicamente, a Ilha era utilizada como fonte de recursos naturais, sobretudo pela qualidade dos mananciais e pela abundância das matas, que servia na época das disputas territoriais luso-espanholas como fonte de madeira para a construção de fortificações (RUIVO, 1994), fato que, devido às constantes incursões de marinheiros para a coleta de recursos, deu à localidade o nome "dos Marinheiros".

A conjugação desses elementos propiciou que a região fosse massivamente colonizada e se tornasse significativa para a produção agrícola do município. Conforme consta em Azevedo (2003), a Ilha chegou a atingir o patamar de $70 \%$ 
da produção de hortifrutigranjeiros consumidos no município de Rio Grande. Em contraste, devido à falta de condições de trabalho em função da concorrência tecnológica, hoje se presencia uma expressiva redução populacional. O último censo $^{8}$ (que especificou as características demográficas da Ilha) aponta a existência de 1324 habitantes, distribuídos em 350 famílias e 445 domicílios, sendo a maior parte da população composta por crianças e idosos. A maioria dos jovens em idade produtiva migrou ao continente em busca de melhores condições de trabalho e estudo para os filhos. Apenas uma escola na ilha oferece o ensino fundamental completo. Não há projetos de continuidade: os mais velhos esperam a morte; os mais novos, a maior idade (RECUERO, 2006).

Atualmente, as principais atividades econômicas da Ilha se encontram na agricultura e na pesca. A criação de animais, ainda bastante praticada, destinase exclusivamente a prover o consumo familiar. Em escala reduzida, ainda há casos isolados de produção artesanal de Jurupiga (bebida típica da região) e produção de flores para o dia de finados, outrora usuais fontes de renda.

Por conta da falta de políticas governamentais de assistência, os que ainda ali vivem enfrentam problemas de toda ordem para dar continuidade ao processo de produção. Não há segurança, a educação é básica, o acesso à saúde é limitado. A falta de comunicação da Ilha com o continente, no que se refere à dificuldade do transporte dos produtos hortifrutigranjeiros, aponta-se também como uma das razões que propiciaram a estagnação do crescimento econômico da região (AZEVEDO, 2003). O acesso de veículos à ilha se dava somente por uma balsa. Os ilhéus transportavam a produção necessariamente por via lacustre, o que prejudicava a comercialização ${ }^{9}$.

Quanto ao modelo agrícola, a Ilha dos Marinheiros apresenta características sustentáveis de produção, embora se constate recentemente a inserção, ainda que em menor escala, de práticas inorgânicas (agrotóxicos e fertilizantes artificiais). O preparo do solo é feito manualmente, a adubação normalmente se restringe ao uso de esterco, macega e resíduos de pescado: 
exemplos ilustrativos da utilização dos recursos locais em abundância de maneira sustentável (MANZONI, 2007).

A área produtiva da Ilha soma aproximadamente $12,58 \mathrm{~km}^{2}$. As propriedades distribuem-se, em sua maioria, em pequenos lotes. São subdividas em função da partilha entre herdeiros. As terras são trabalhadas normalmente em canteiros de 1,20 metro de largura e 20 metros de comprimento. Não há empregados, o trabalho é realizado pelos membros da família. Em geral em todos os grupos familiares de produção são cultivadas as mesmas espécies de hortaliças. A comercialização da produção é variada. Algumas famílias vendem a grandes redes de varejo, outras em feiras-livres em Rio Grande, mas grande parte da produção ainda é comercializada no Terminal Hortifrutigranjeiro no cais do porto do município. 


\section{Narrativa estrutural ${ }^{10}$}
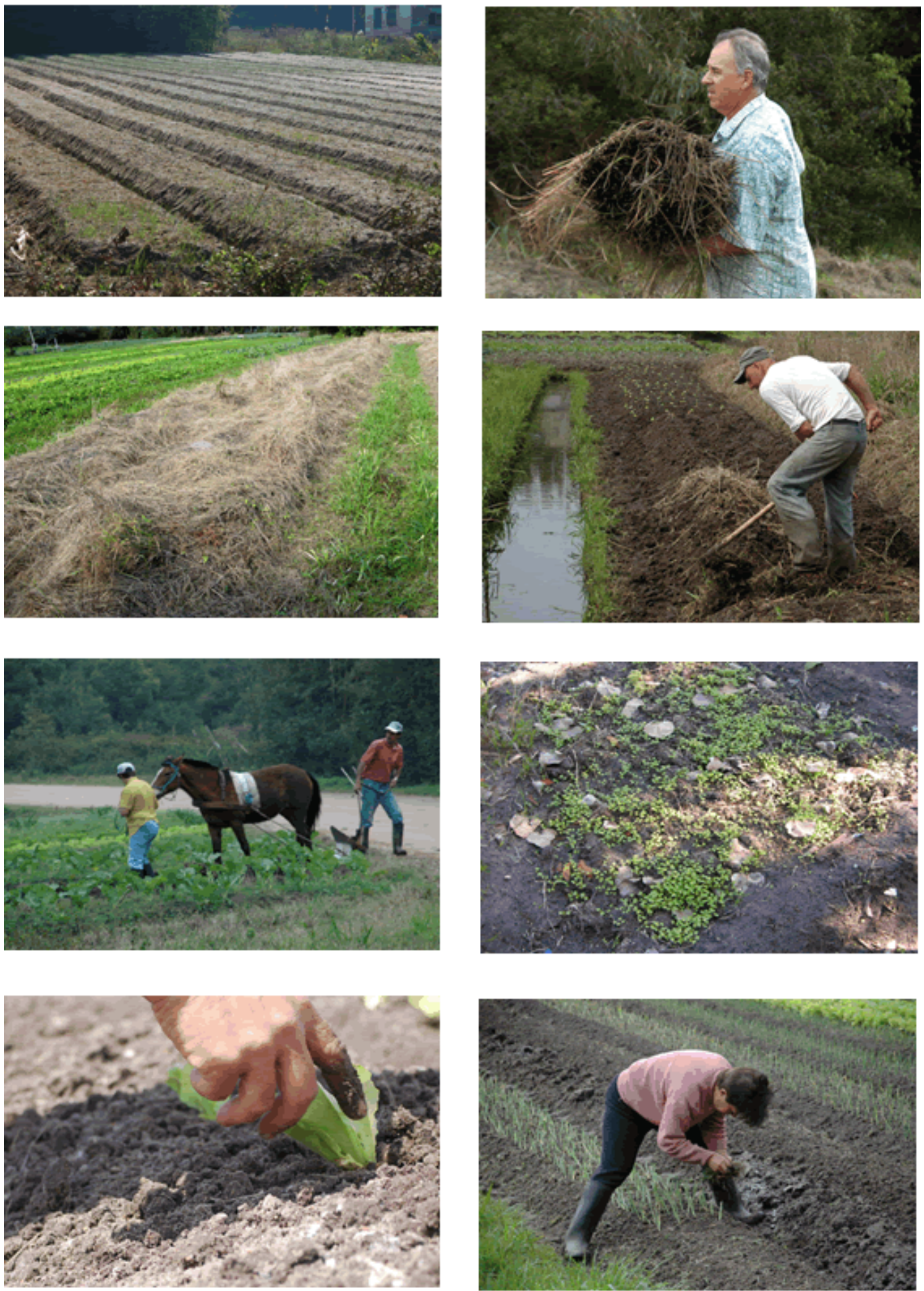

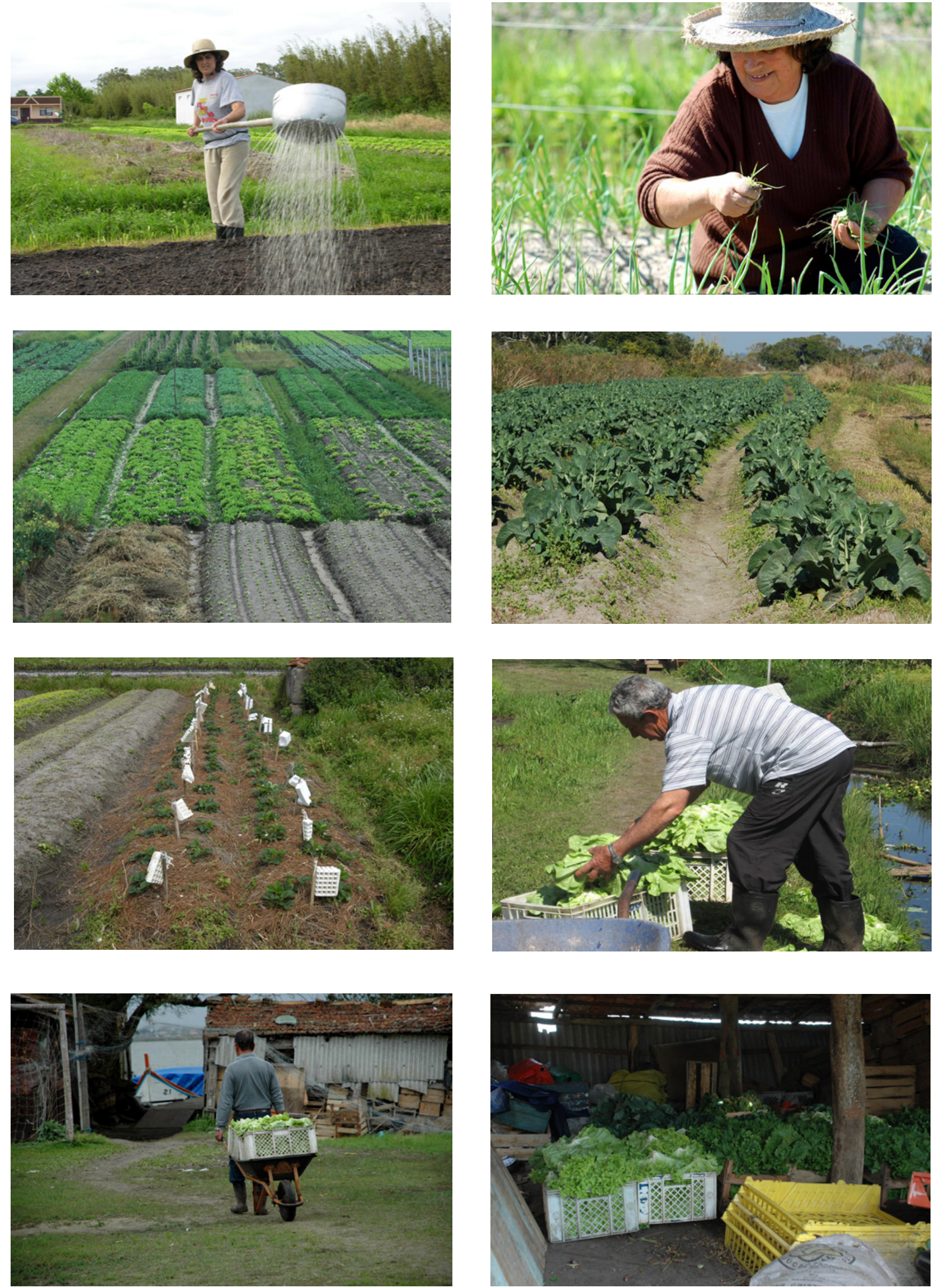

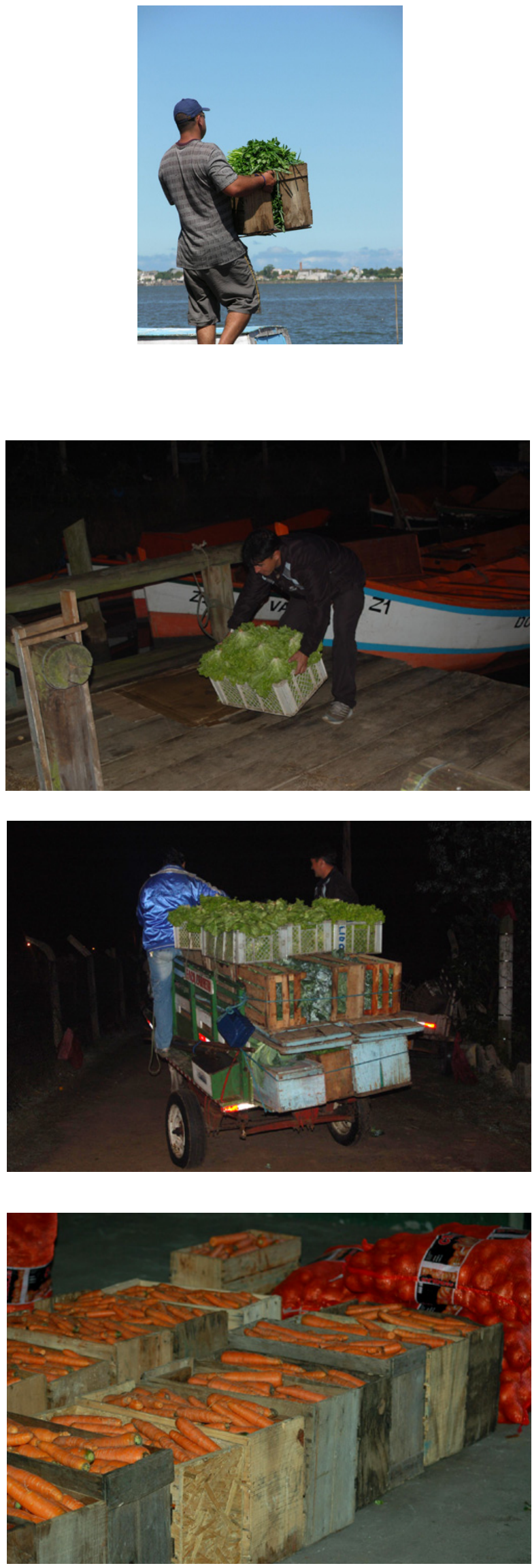
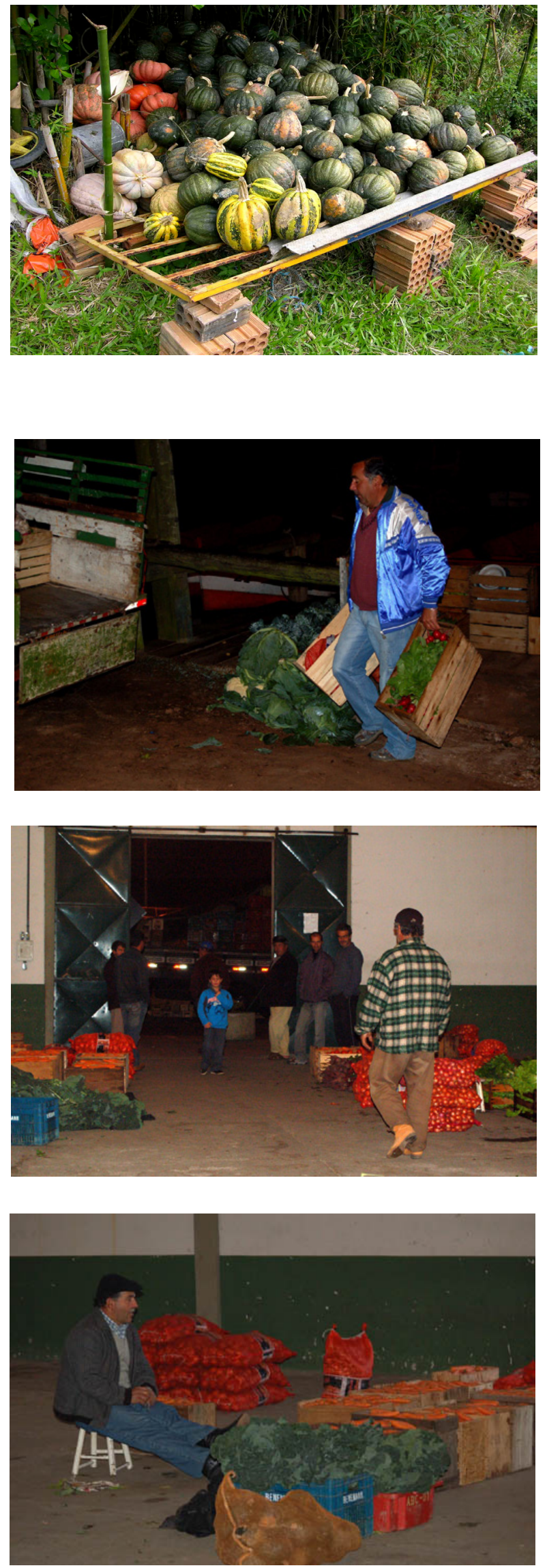


\section{Considerações finais}

Buscou-se realizar com a presente pesquisa um estudo fotoetnográfico da Ilha dos Marinheiros, a fim de registrar as suas características culturalmente peculiares que, em pleno século XXI, ainda que de forma parcial, resistem aos processos globalizantes dos novos tempos. Para tanto, o foco deste trabalho recaiu sobre o modelo agrícola, uma das atividades econômicas historicamente presentes daquele universo que ainda persiste a duras penas perante as novas perspectivas de produção, principalmente pela competição tecnológica oferecida pelas agroindústrias.

A utilização da fotografia como resgate cultural se mostra relevante, uma vez que se fixa a realidade, perpetua-se a memória da singularidade cultural de uma comunidade (dissidente) através de uma nova forma discursiva - o uso de fotografias como discurso narrativo. Essa nova visão sobre a comunicação, do fazer uma leitura do mundo social através do suporte fotográfico, permitiu-nos registrar a força da imagem fotográfica como formadora de uma consciência social, cultural, emocional e educacional dos ilhéus em face à percepção de suas realidades.

Acreditamos que a partir dos resultados desta pesquisa, principalmente pela visualização das narrativas fotográficas, que descrevem um modo hoje mercadologicamente atípico e ao mesmo tempo sustentável de produção, possa-se difundir a realidade da Ilha dos Marinheiros de forma a incentivar políticas sociais que visem ao desenvolvimento daquela região. Nesse sentido, conclui-se que a concorrência tecnológica das agroindústrias pode ser enfrentada e capitalizada em favor do progresso econômico da Ilha a partir da divulgação de sua forma de produção, valorizando assim a qualidade dos seus produtos hortifrutigranjeiros em razão de se tratar, em grande parcela, de uma produção ecologicamente correta. 
Em suma, a Ilha hoje vive o contraste entre os processos globalizantes do terceiro milênio em contraposição ao passado de produção artesanal trazidos pela colonização portuguesa. Ao mesmo tempo em que se aponta o atraso tecnológico e a precariedade do modo de produção agrícola, far-se uma ressalva quanto à sustentabilidade desse modelo, reproduzido desde o final do século XVIII até os dias de hoje. Assim, a fala de Azevedo (2003, p. 12), "a ilha do passado, do presente e do futuro", passa carregar um novo significado: a sustentabilidade. Através da construção de narrativas fotográficas, o objetivo desta pesquisa é dar vazão a essa perspectiva. 


\section{Referências}

ACHUTTI, L. Fotoetnografia, um estudo de antropologia visual sobre cotidiano, lixo e trabalho. Porto Alegre: Tomo Editorial; Palmarinca, 1997.

. Fotoetnografia da Biblioteca Jardim. Porto Alegre: Tomo Editorial/ UFRGS Editora, 2004.

AZeVedo, A. "A Ilha dos Três Antônios". Jornal Soberania do Povo. Portugal, 2003.

BATESON, G. \& MEAD, M. Balinese Character. A Photographic Analysis. The New Academy of Sciences, 1962.

BRITO, F. "Os povos em movimento: as migrações internacionais no desenvolvimento do capitalismo". In: PATARRA, N. L. (Org.). Emigração e imigração internacional no Brasil contemporâneo. Campinas: Fnaup, 1995.

COLLIER JR, J. Antropologia visual: a fotografia como método de pesquisa. São Paulo: Edusp, 1973.

CORRÊA, A. A legislação imigratória brasileira e seus reflexos para o acontecer dos direitos humanos. Dissertação de mestrado. São Leopoldo: Unisinos, 2005.

FERREIRA, G. "Paradigmas do Campo Comunicacional relacionados com a Antropologia". Salvador: Anais do XXV Congresso de Ciências da Comunicação, 2002.

MALINOWSKI, B. Argonautas do Pacífico Ocidental: Um relato do empreendimento e da aventura dos nativos nos arquipélagos da Nova Guiná Melanésia. Coleção Os Pensadores. São Paulo: Abril Cultural, 1978.

MANZONI, J. Estratégias de manejo utilizando indicadores de sustentabilidade: o agroecossistema da Ilha dos Marinheiros. Guaíba: Agrolivros, 2007.

RECUERO, C. "Ilha dos Marinheiros: um estudo etnofotográfico para a construção da identidade social". In: Ecos Revista, Pelotas, 2006.

RUIVO, J. "Contribuição para a história da Ilha dos Marinheiros, Rio Grande - RS". In: ALVES, F. e TORRES, L. (orgs.). Temas de história do Rio Grande do Sul. Rio Grande: Editora Furg, 1994. 
ZANOTELLI, J. Rio Grande do Sul: arquétipos culturais e desenvolvimento social. Pelotas: Educat, 2000.

SAMAIN, E. (Org.). O fotográfico. São Paulo: Hucitec, 1998.

SAMAIN, E. "'Ver' e 'dizer' na tradição etnográfica: Bronislaw Malinowski e a fotografia". In: Horizontes Antropológicos. Porto Alegre: Editora da UFRGS, n 2, p. 19. . "Balinese character (re)visitado". In: ALVES, A. Os argonautas do mangue. Campinas: Editora da Unicamp, 2004.

. "Gregory Bateson: rumo a uma epistemologia da comunicação". Ciberlegenda.

Disponível em: http://www.uff.br/mestcii/samain1.htm. Acesso em: abril de 2008.

. Organização e apresentação. Campinas: Papirus, 1998.

WINKIN, Y. A nova comunicação: da teoria ao trabalho de campo. Papirus. Campinas. 1998.

1 Mestrando do Programa de Pós-Graduação em Comunicação da PUC-RS. Bacharel em Comunicação Social - Habilitação em Jornalismo pela Universidade Católica de Pelotas (UCPel, 2009). Email: jandrecb@ gmail.com.

2 Nomenclatura de Achutti (2004). 
3 Etnografia no século XIX era entendida como uma contemplação ao exótico. O procedimento etnográfico consistia em enviar questionários a viajantes e coletar objetos da cultura local que se julgassem atrativos pela suas características/funções singulares. A partir de Malinowski, os atores sociais das culturas em estudo deixaram de ser observados "como graciosos animais exóticos, mas, sim, como pessoas dignas de respeito, cuja vida social se deve tentar reconstituir" (...) (WINKIN, 1998, p. 130).

4 A seguinte passagem é ilustrativa dessa situação: "Imagine-se o leitor rodeado apenas de seu equipamento, numa praia tropical próxima a uma aldeia nativa, vendo a lancha ou o barco que o trouxe afastar-se no mar até desaparecer de vista" (MALINOWSKI, 1976, p. 23).

5 A título de exemplificação, Achutti (2004, p. 105) faz referência à limitação de Malinowski ao uso da fotografia em citação a Young (1998): "Sua insatisfação com relação aos resultados que obtinha se devia tanto às características técnicas limitadas das câmeras e dos filmes de sua época como às suas próprias limitações, e fica justificada quando se sabe que ele (Malinowski) errou o foco de quase metade das mil e cem fotografias arquivadas no London School of Economics". Winkin (1998) critica o uso de câmeras fotográficas e gravadores nesse sentido. IBGE, 2000.

9 Hoje o acesso de veículos à Ilha dos Marinheiros é realizado através de uma ponte, finalizada em 2004, que passou a permitir a comunicação da Ilha com o continente por intermédio da Ilha do Leonídio.

10 Fotografias do Acervo do Projeto Fotográfico Ilha dos Marinheiros da Universidade Católica de Pelotas (UCPel). As imagens aqui apresentadas são de autoria do próprio autor (19), de Carlos Leonardo Recuero (2), Andressa Almeida Barros (2) e Paulo Azambuja (1). 